\title{
Impact of amplifier errors on position loop accuracy of high- precision moving stages
}

\section{Citation for published version (APA):}

Settels, S. J., Duarte, J. L., \& van Duivenbode, J. (2017). Impact of amplifier errors on position loop accuracy of high-precision moving stages. In 2017 19th European Conference on Power Electronics and Applications (EPE'17 ECCE Europe), 11-14 September 2017, Warsaw, Poland (pp. P.1 - P.10). [8099009] Institute of Electrical and Electronics Engineers. https://doi.org/10.23919/EPE17ECCEEurope.2017.8099009

DOI:

10.23919/EPE17ECCEEurope.2017.8099009

Document status and date:

Published: 13/09/2017

\section{Document Version:}

Accepted manuscript including changes made at the peer-review stage

\section{Please check the document version of this publication:}

- A submitted manuscript is the version of the article upon submission and before peer-review. There can be important differences between the submitted version and the official published version of record. People interested in the research are advised to contact the author for the final version of the publication, or visit the $\mathrm{DOI}$ to the publisher's website.

- The final author version and the galley proof are versions of the publication after peer review.

- The final published version features the final layout of the paper including the volume, issue and page numbers.

Link to publication

\section{General rights}

Copyright and moral rights for the publications made accessible in the public portal are retained by the authors and/or other copyright owners and it is a condition of accessing publications that users recognise and abide by the legal requirements associated with these rights.

- Users may download and print one copy of any publication from the public portal for the purpose of private study or research.

- You may not further distribute the material or use it for any profit-making activity or commercial gain

- You may freely distribute the URL identifying the publication in the public portal.

If the publication is distributed under the terms of Article 25fa of the Dutch Copyright Act, indicated by the "Taverne" license above, please follow below link for the End User Agreement:

www.tue.nl/taverne

Take down policy

If you believe that this document breaches copyright please contact us at:

openaccess@tue.nl

providing details and we will investigate your claim. 


\title{
Impact of Amplifier Errors on Position Loop Accuracy of High-Precision Moving Stages
}

\author{
S.J. Settels, J. van Duivenbode, J.L. Duarte \\ Eindhoven University of Technology \\ De Rondom 70 \\ Eindhoven, The Netherlands \\ Email: s.settels@tue.nl \\ URL: http://www.tue.nl/epe
}

\section{Keywords}

$\ll$ Amplifiers $\gg, \ll$ Mechatronics $\gg, \ll$ Modelling $\gg, \ll$ Motion control $\gg$.

\begin{abstract}
To maximise essential system performance parameters, this research combines electrical, mechanical and position control models of a high-precision mechatronic system. The degradation of system performance induced by identified amplifier errors is analysed to reveal the significance of each error mechanism. The simplified outline of a mechatronic system is given to which models of the power amplifier are added in order to emulate the error mechanisms. Analysis of the impact of each error mechanism on the position accuracy of the mechatronic system is given from which specifications for the power amplifier can be obtained for a certain required position accuracy. Ensuing properly targeted requirements provide focused amplifier optimisation.
\end{abstract}

\section{Introduction}

Industrial applications using fast-moving high-precision stages, e.g. lithographic equipment (see Fig. 1 [1]), require power amplifiers with high-precision output current generation capabilities. Errors produced by the amplifier with respect to the current reference influence the stationary and dynamic positioning accuracy of a high-precision mechatronic system [2,3]. Current research focuses on the improvement of the performance of high-precision amplifiers, e.g. [4, 5], and position control of high-precision stages, e.g. $[1,6,7]$, independently. However, the influence of the performance of the amplifier on the position accuracy of the moving stage has not been analysed yet.

This research combines (simplified) models of mechanical, electrical and position control systems and provides insight in the significance of error mechanisms incorporated in the amplifier. This allows to

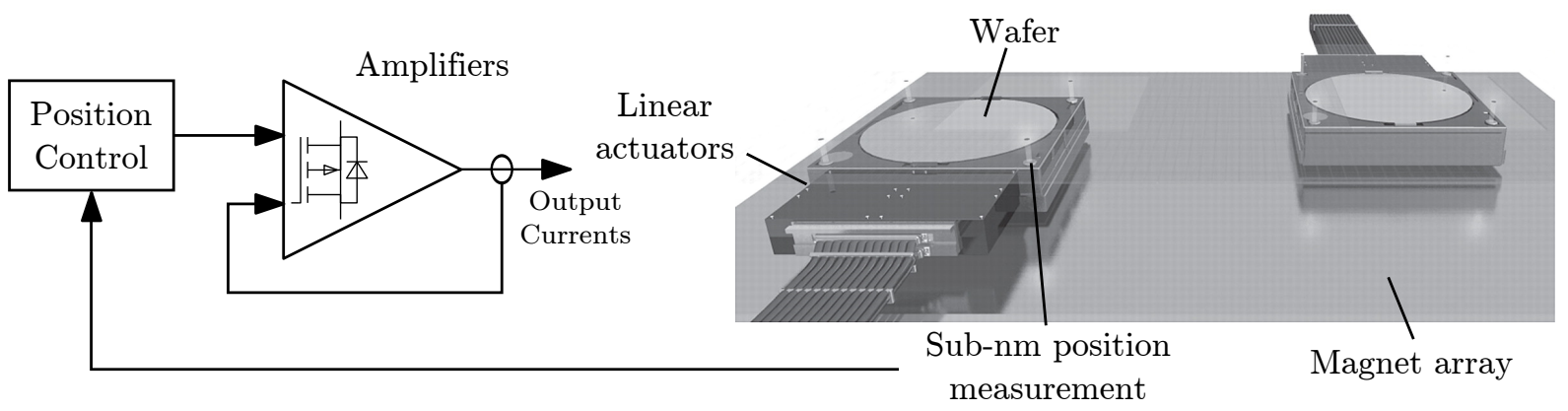

Fig. 1: Outline of high-precision wafer positioning system. (Courtesy of ASML [1]) 
deduce a set of requirements for the performance of the amplifier for a given maximum allowed position error for the complete system. Furthermore, it enables a more efficient design process of the power electronics, where errors are anticipated and resolved before the design is cast into costly prototypes.

A generic approach to model the position control of an electromechanical system is introduced [8], to which models for the amplifier are added in order to emulate error mechanisms. The starting point is the ideal amplifier represented by a gain of one and zero phase distortion, to which the respective error mechanisms are added: offset current, gain error and non-linearity error; the latter being modelled using current-spatial frequencies [9]. Furthermore, a model of a current-controlled current amplifier with load, comprising closed-loop output current control, is used to simulate the bandwidth limitation and corresponding phase-shift of the amplifier [3]. For each error mechanism, the resulting influence on the positioning accuracy of the mechatronic system is evaluated. Requirements for the performance of the power amplifier can then be deduced for given required stationary and dynamic position accuracies.

\section{Position control of electromechanical systems}

A model of a high-precision moving stage, as shown in Fig. 1, incorporating movement in a single direction, is analysed in this research. The global outline of the position control system of the electromechanical system is shown in Fig. 2. The electromechanical plant $P(s)$ consists of a (simplified) motor model with a motor constant $k_{\mathrm{m}}$ to calculate the force from the current generated by the amplifier, and a mass $m$ and damping $c$ to which the force is applied [10]. The actual position $x_{\text {out }}$ of the moving mass $m$, obtained from the transfer function of $P(s)$, is fed back to the position controller $C(s)$. Together with a feed forward transfer function $H_{\mathrm{FF}}(s)$, consisting of an inverse of estimates of the actual electromechanical plant, the current setpoint $i_{\text {set }}$ for the amplifier is generated [8]. The position controller $C(s)$ is a standard PID controller which is designed for an open-loop bandwidth $f_{\mathrm{bw}, \text { pos }}$. The corresponding transfer functions are defined as

$$
\begin{aligned}
P(s) & =\frac{k_{\mathrm{m}}}{m s^{2}+c s} \\
H_{\mathrm{FF}}(s) & =\frac{1}{\hat{P}(s)}=\frac{\hat{m} s^{2}+\hat{c} s}{\hat{k_{\mathrm{m}}}} \\
C(s) & =\frac{K_{\mathrm{D}} s^{2}+K_{\mathrm{P}} s+K_{\mathrm{I}}}{\hat{k_{\mathrm{m}}} s} .
\end{aligned}
$$

The values of the estimated parameters $\hat{m}, \hat{c}$ and $\hat{k_{\mathrm{m}}}$, are taken equal to the actual parameter values as the aim is to assess amplifier error impact only. Note that the transfers of (2) and (3) are still noncausal.

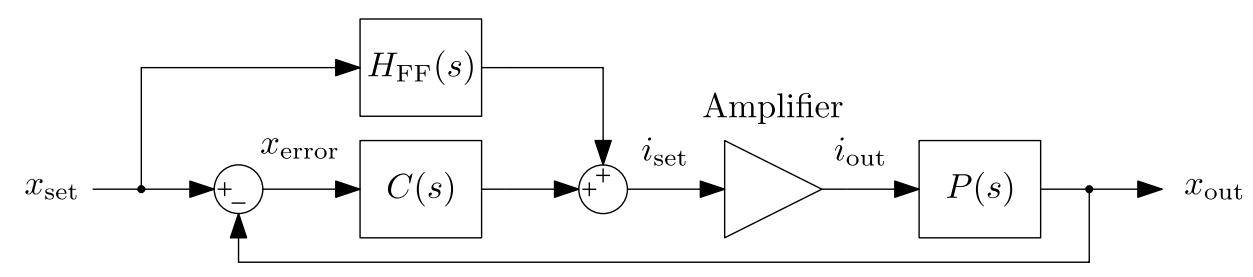

Fig. 2: Global outline of the position control system.

To obtain very high positioning accuracy, it is essential that the input position setpoint $x_{\text {set }}$ is delayed with the same amount as the total time delay in the feed forward path, comprising of $H_{\mathrm{FF}}(s)$, the amplifier and $P(s)$ [6]. In order to achieve this when the system is transformed to the discrete domain with a sample frequency of $f_{\mathrm{s} \text {,pos }}$, the input of the feedback subtracter is delayed with a fixed integer number of samples $\beta$ and the input of $H_{\mathrm{FF}}(s)$ is delayed with a tunable fractional number of samples $\alpha$ using the interpolating delay function

$$
H_{\text {delay }}(z)=\alpha+(1-\alpha) z^{-1} .
$$


Fig. 3 shows the resulting discrete position control model with the added delays $H_{\text {delay }}(z)$ and $z^{-\beta}$, and a Zero-Order Hold $(\mathrm{ZOH})$ block to convert the actual position from the continuous domain to the discrete domain with sample frequency $f_{\mathrm{s} \text {,pos. }} H_{\mathrm{FF}}(z)$ and $C(z)$ represent the discrete time models of the feedforward transfer function and position controller to which additional delays are added to make them causal.

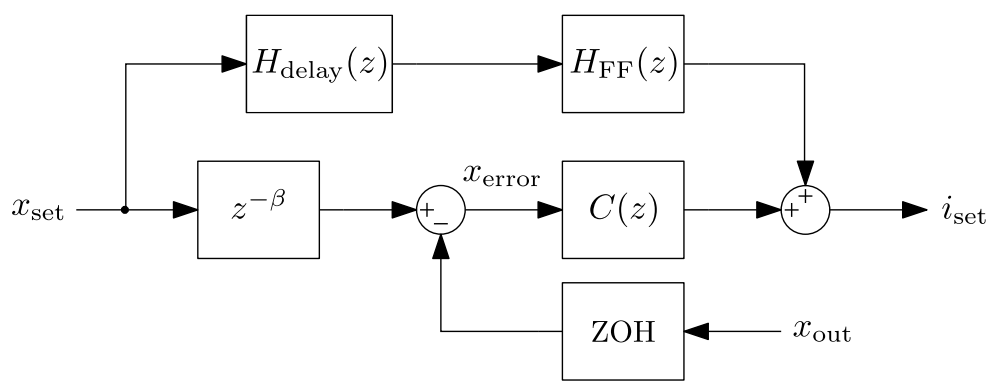

Fig. 3: Outline of the discrete position control model including delays $H_{\text {delay }}(z)$ and $z^{-\beta}$.

A 3rd order motion profile with trapezoidal acceleration, consisting of velocity $v$, acceleration $a$, and jerk $j$, is used for the position input setpoint $x_{\text {set }}$ (see Fig. 4 for a normalized representation).

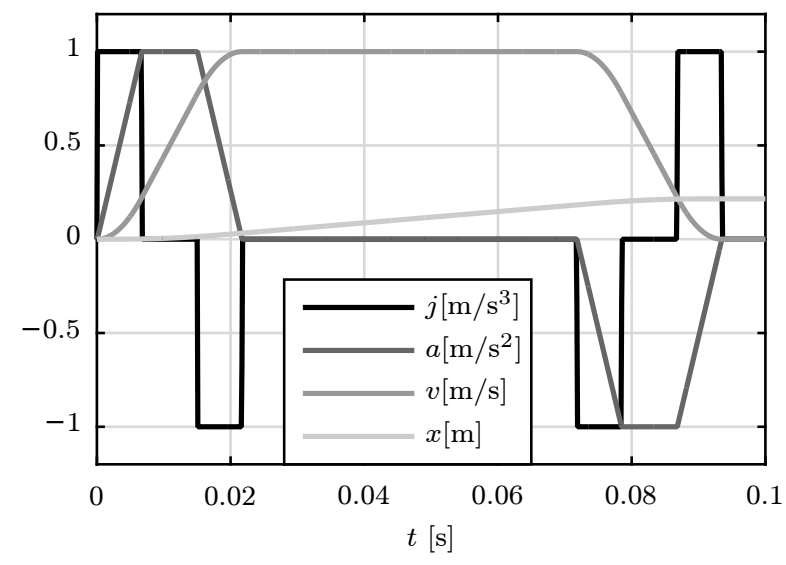

Fig. 4: Normalized representation of the 3rd order motion profile used as position input.

\section{Amplifier error modelling}

Non-idealities of the amplifier are modelled in this research by means of two types of errors: additive current errors (offset, gain and non-linearity), and bandwidth limitation. Potential sources of amplifier errors are for instance non-idealities in current sensors, inductors, switching end-stages, signal processing and control [9].

\section{Additive current errors}

The potential current errors discussed in this research are offset current, gain error and non-linearity error [9]. A schematic outline of the amplifier additive current error model is shown in Fig. 5. A generic model is depicted that is independent from actual implementation of the amplifier. The respective error currents $i_{\text {offset }}, i_{\text {gainerror }}$ and $i_{\text {nonlin }}$ are added, resulting in $i_{\text {error }}$ which is added to $i_{\text {set }}$ to obtain the modelled amplifier output current. A ZOH block is added at the input to convert $i_{\text {set }}$ from the sample rate of the position loop $f_{\mathrm{s} \text {,pos }}$ to the sample rate of the current loop $f_{\mathrm{s}, \mathrm{cur}}$, which corresponds with the fixed-step size at which the discrete amplifier and mechanical plant models are simulated.

While the implementation of the offset current and gain error is straightforward, for the generation of $i_{\text {nonlin }}$ more explanation is required. A dimensionless current-spatial frequency $f_{\text {spat }}[\mathrm{A} / \mathrm{A}]$ is defined to obtain non-linear components as a function of $i_{\text {set }}$. A single frequency component, induced by nonlinear behaviour of the amplifier (e.g. originating from current sensor or switching end-stage), is thereby 


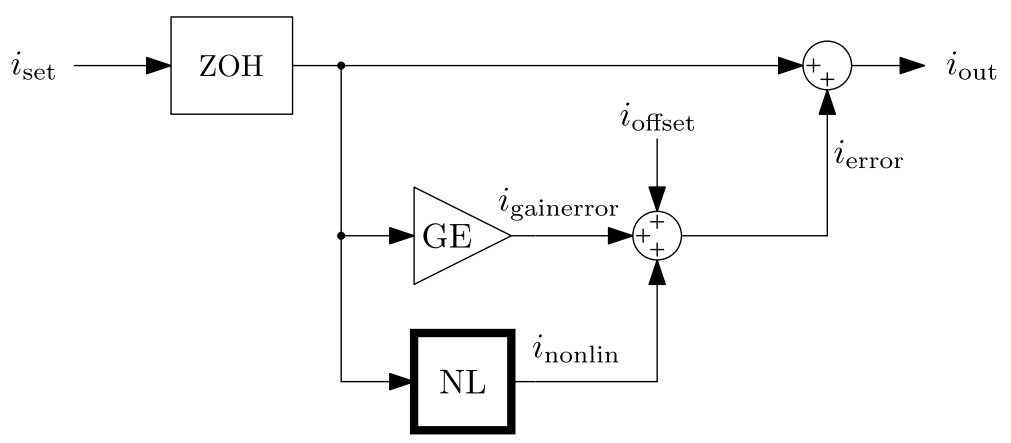

Fig. 5: Schematic representation of the amplifier model, containing additive current errors.

superimposed to the spectrum of $i_{\text {set }}$. The performance of the system is subsequently evaluated for a range of current-spatial frequencies corresponding to the applicable frequency range of $i_{\text {set }}$.

Even and odd functions of $i_{\text {nonlin }}$ as a function of $i_{\text {set }}$ and $f_{\text {spat }}$ are defined and given by

$$
\begin{aligned}
i_{\text {nonlin,even }} & =I_{\mathrm{NL}} \cdot \cos \left(2 \pi f_{\text {spat }} \frac{i_{\text {set }}}{I_{\max }}\right) \\
i_{\text {nonlin,odd }} & =I_{\mathrm{NL}} \cdot \sin \left(2 \pi f_{\text {spat }} \frac{i_{\text {set }}}{I_{\max }}\right)
\end{aligned}
$$

where $I_{\mathrm{NL}}$ is the non-linearity current amplitude and $I_{\max }$ defines the applicable current range.

Example plots of both equations for $f_{\text {spat }}=0.5[\mathrm{~A} / \mathrm{A}]$ and $f_{\text {spat }}=3[\mathrm{~A} / \mathrm{A}]$ are shown in Fig. 6 and Fig. 7 for the even and odd functions respectively.

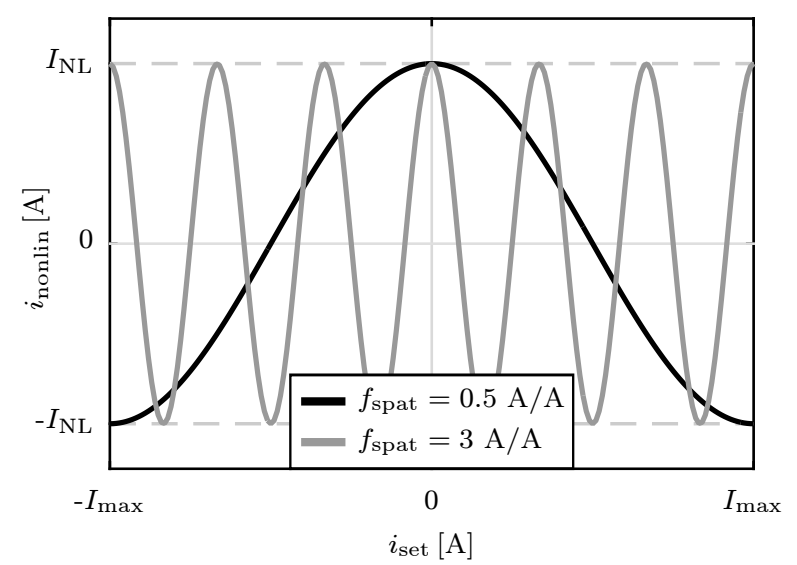

Fig. 6: Example plot of $i_{\text {nonlin }}$ as a function of $i_{\text {set }}$ for $f_{\text {spat }}=0.5 \mathrm{~A} / \mathrm{A}$ and $f_{\text {spat }}=3 \mathrm{~A} / \mathrm{A}$, regarding even non-linearity.

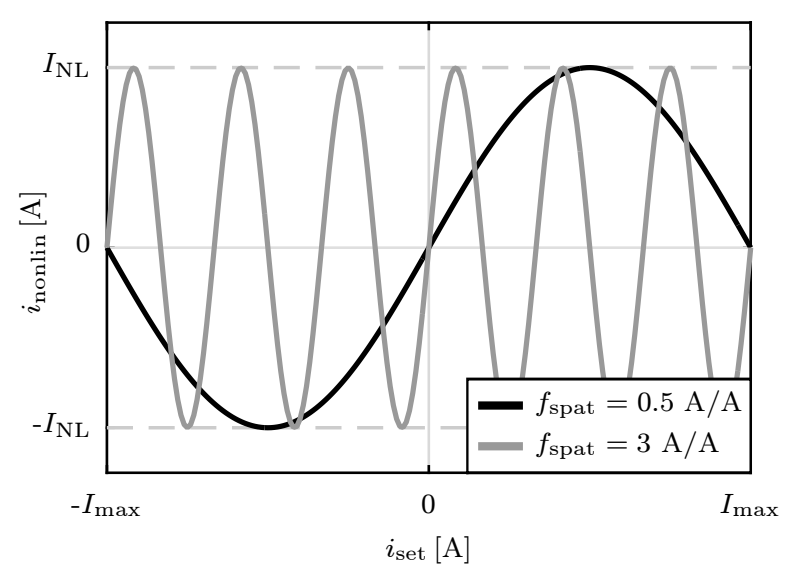

Fig. 7: Example plot of $i_{\text {nonlin }}$ as a function of $i_{\text {set }}$ for $f_{\text {spat }}=0.5 \mathrm{~A} / \mathrm{A}$ and $f_{\text {spat }}=3 \mathrm{~A} / \mathrm{A}$, regarding odd non-linearity.

\section{Bandwidth limitation}

The generic control outline of a current-controlled current amplifier is shown in Fig. 8 with an electrical plant $P_{\mathrm{e}}$, an output current controller $C_{\mathrm{e}}$ with a direct feed forward path, and an anti-aliasing filter $H_{\mathrm{AA}}$ [3]. The anti-aliasing filter is required in a practical implementation, and since it influences the closedloop control characteristics of the system, it is therefore included in the model. Furthermore, a ZOH block is added at the input to convert the sample rate of $i_{\text {set }}$ from $f_{\mathrm{s}, \text { pos }}$ to $f_{\mathrm{s}, \mathrm{cur}}$, the fixed-step size at which the model is simulated.

An equivalent electrical circuit schematic of $P_{\mathrm{e}}$ is shown in Fig. 9 with output capacitor $C_{\mathrm{f}}$, load characteristics $R_{\mathrm{o}}, L_{\mathrm{o}}$, and a voltage source emulated EMF. The resonance of $C_{\mathrm{f}}$ and $L_{\mathrm{o}}$ is actively damped to a Butterworth characteristic by subtracting the measured capacitor voltage $v_{\mathrm{Cf}}$, multiplied with damping 


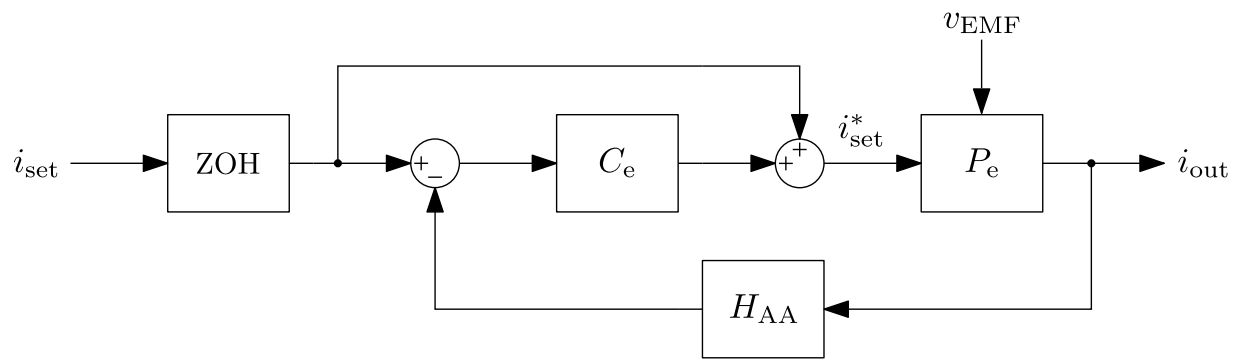

Fig. 8: Outline of the amplifier current control model.

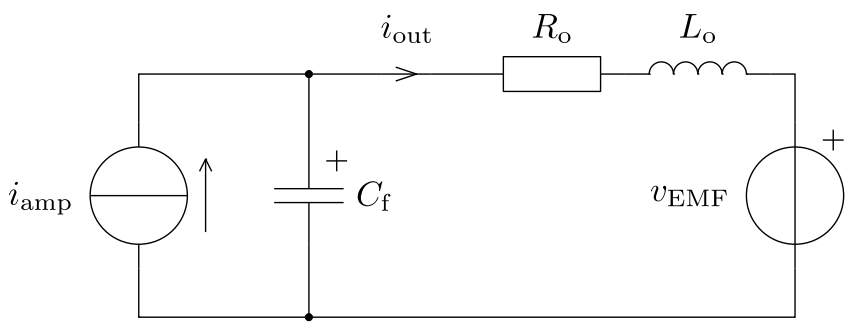

Fig. 9: Schematic representation of electrical plant $P_{\mathrm{e}}$.

factor $K$, from $i_{\text {set }}^{*}$, leading to

$$
\begin{aligned}
i_{\mathrm{amp}} & =i_{\mathrm{set}}^{*}-K \cdot v_{\mathrm{Cf}} \\
K & =\sqrt{2 \cdot \frac{C_{\mathrm{f}}}{L_{\mathrm{o}}}} .
\end{aligned}
$$

A state-space model is derived from the differential equations of the actively damped circuit in Fig. 9, resulting in

$$
\left[\begin{array}{c}
\dot{i_{\mathrm{Lf}}} \\
v_{\mathrm{Cf}}
\end{array}\right]=\left[\begin{array}{cc}
-\frac{R_{\mathrm{o}}}{L_{\mathrm{o}}} & \frac{1}{L_{\mathrm{O}}} \\
-\frac{1}{C_{\mathrm{f}}} & -\frac{K}{C_{\mathrm{f}}}
\end{array}\right]\left[\begin{array}{c}
i_{\mathrm{Lf}} \\
v_{\mathrm{Cf}}
\end{array}\right]+\left[\begin{array}{c}
0 \\
\frac{1}{C_{\mathrm{f}}}
\end{array}\right] i_{\text {set }}^{*} .
$$

The current controller $C_{\mathrm{e}}$ is of the PID type, with

$$
C_{\mathrm{e}}(s)=\frac{K_{\mathrm{D}} s^{2}+K_{\mathrm{P}} s+K_{\mathrm{I}}}{s}
$$

which is tuned for an open-loop bandwidth $f_{\mathrm{bw}, \mathrm{cur}}$ for the example in this section. The Bode diagrams of the discrete-time models with sample frequency $f_{\mathrm{s}, \mathrm{cur}}$ for the electrical plant $P_{\mathrm{e}}$, current controller $C_{\mathrm{e}}$, anti-aliasing filter $H_{\mathrm{AA}}$, and resulting open-loop gain $H_{\mathrm{AA}} P_{\mathrm{e}} C_{\mathrm{e}}$ are shown in Fig. 10. The anti-aliasing filter is a $2^{\text {nd }}$ order Butterworth low-pass filter with a cut-off frequency of $f_{\mathrm{co}}=4 f_{\mathrm{bw}, \mathrm{cur}}$.

\section{Simulation results}

To obtain insight in the influence of amplifier errors on positioning accuracy, the mechanical, electrical and control system models are combined into a single simulation platform. The resulting position error $x_{\text {error }}$ is determined after a settling time of $t_{\text {settling }}=3 \mathrm{~ms}$ when acceleration $a=0 \mathrm{~m} / \mathrm{s}^{2}$ and jerk $j=0 \mathrm{~m} / \mathrm{s}^{3}$ after accelerating from standstill to constant speed (see Fig. 11).

For imaging (lithographic) applications, two aspects of the position error of the moving stage are critical to its dynamic performance: low-frequency position error defined by MA (Moving Average), determining the absolute error; and a high-frequency part defined by MSD (Moving Standard Deviation), 

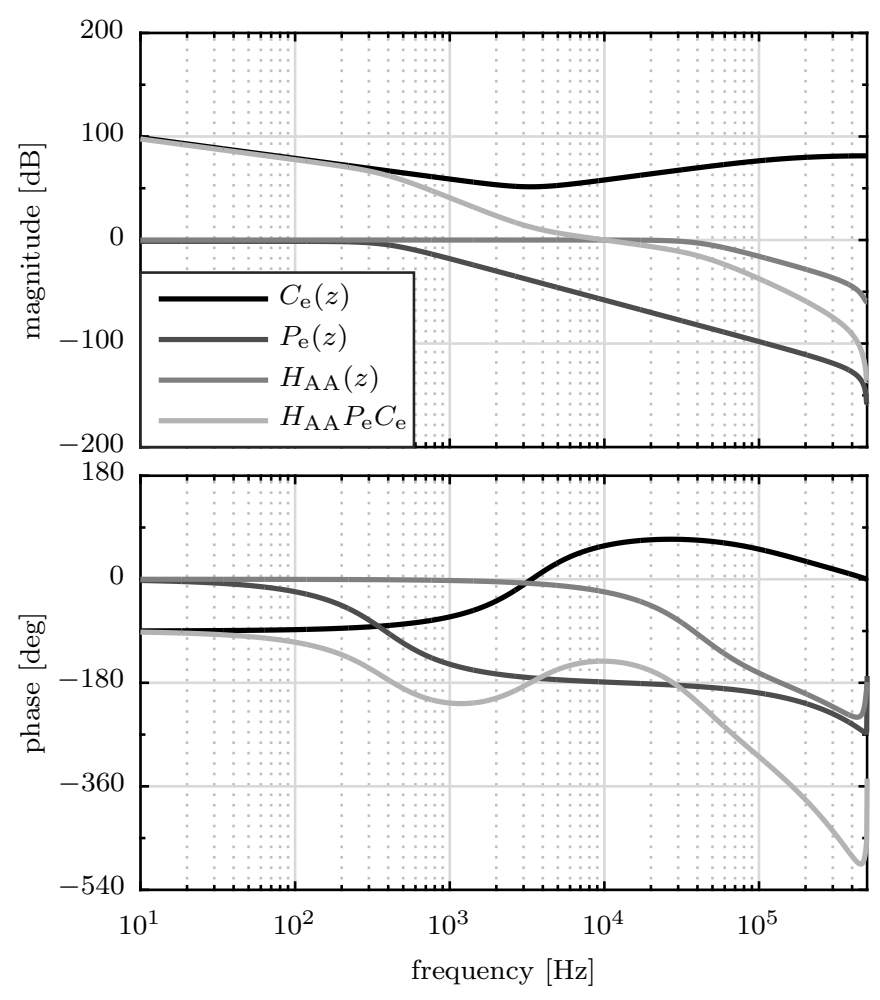

Fig. 10: Bode diagram of the discrete-time models with sample frequency $f_{\mathrm{s}, \mathrm{cur}}$ for the electrical plant $P_{\mathrm{e}}$, current controller $C_{\mathrm{e}}$, anti-aliasing filter $H_{\mathrm{AA}}$, and resulting open-loop gain $H_{\mathrm{AA}} P_{\mathrm{e}} C_{\mathrm{e}}$.

determining image contrast loss; as defined in [10]. The MA/MSD cross-over frequency between lowfrequency and high-frequency position error is $f_{\mathrm{co}}=273 \mathrm{~Hz}$ for the system presented in this research. The respective position errors $M A(t)$ and $M S D(t)$ are defined as

$$
\begin{aligned}
M A(t) & =\frac{1}{T} \int_{t-T / 2}^{t+T / 2} e(\tau) d \tau \\
M S D(t) & =\sqrt{\frac{1}{T} \int_{t-T / 2}^{t+T / 2}(e(\tau)-M A(t))^{2} d \tau}
\end{aligned}
$$

where $T$ represents the imaging expose time window, and $e(t)$ the stage position error $x_{\text {error }}$ as a function of time $t$ [10]. When determining the MA and MSD positioning error, the peak value of the respective definition is taken after the settling time $t_{\text {settling }}$ until deceleration, designated with $t_{\mathrm{MA} / \mathrm{MSD}}$ (see Fig. 11 ).

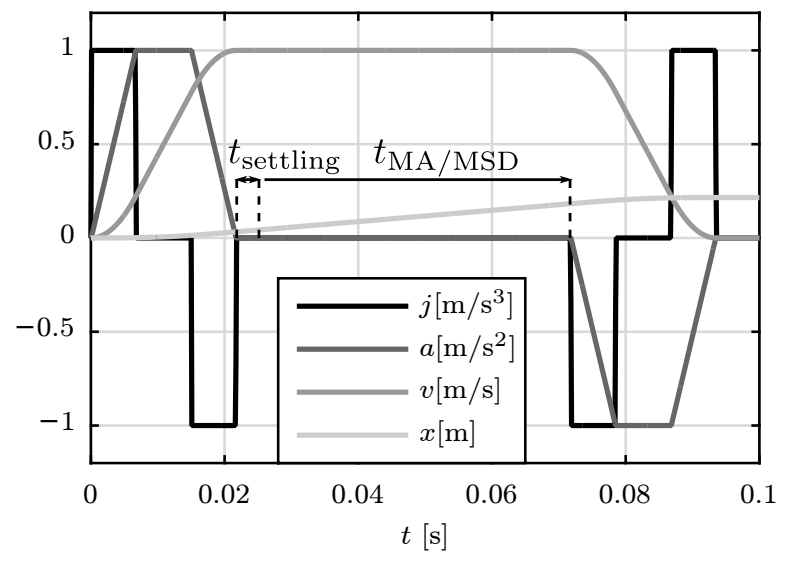

Fig. 11: Motion profile with designated $t_{\text {settling }}$ and $t_{\mathrm{MA} / \mathrm{MSD}}$. 
When an ideal amplifier is used in the simulation platform with the parameters from Table I, the MA and MSD position errors are determined by the more than adequate numerical accuracy of the simulation run in MATLAB Simulink: $M A=0.968 \mathrm{fm}$ and $M S D=0.691 \mathrm{fm}$. The desired position accuracy of the complete system of this research is in the order of $100 \mathrm{pm}$.

The parameters of the mechatronic system analysed in this research, representing a moving stage as shown in Fig. 1 and discussed above, are shown in Table I. Note that the maximum achievable acceleration

$$
a_{\max }=\frac{k_{\mathrm{m}} I_{\max }}{m}=267 \mathrm{~m} / \mathrm{s}^{2}
$$

is more than the specified acceleration $a$. This leaves excitation room required for control and/or tolerances in the system.

Table I: System parameters

\begin{tabular}{c|c|c|l}
\hline \hline Parameter & Value & Unit & Description \\
\hline$k_{\mathrm{m}}$ & 200 & $\mathrm{~N} / \mathrm{A}$ & Electromechanical \\
$m$ & 75 & $\mathrm{~kg}$ & plant \\
$c$ & 200 & $\mathrm{Ns} / \mathrm{m}$ & \\
\hline$v$ & 3 & $\mathrm{~m} / \mathrm{s}$ & Acceleration \\
$a$ & 200 & $\mathrm{~m} / \mathrm{s}^{2}$ & profile \\
$j$ & $3 \cdot 10^{4}$ & $\mathrm{~m} / \mathrm{s}^{3}$ & \\
\hline$f_{\mathrm{s}, \text { pos }}$ & 20 & $\mathrm{kHz}$ & Position \\
$f_{\mathrm{bw}, \text { pos }}$ & 500 & $\mathrm{~Hz}$ & controller \\
\hline$R_{\mathrm{o}}$ & 5 & $\Omega$ & Electrical \\
$L_{\mathrm{o}}$ & 20 & $\mathrm{mH}$ & plant \\
$C_{\mathrm{f}}$ & 10 & $\mu \mathrm{F}$ & \\
\hline$f_{\mathrm{s}, \mathrm{cur}}$ & 1 & $\mathrm{MHz}$ & Current \\
$f_{\mathrm{bw}, \mathrm{cur}}$ & 10 & $\mathrm{kHz}$ & controller \\
\hline$I_{\mathrm{NL}}$ & 0.04 & $\mathrm{~A}$ & Non-linearity \\
$I_{\mathrm{max}}$ & 100 & $\mathrm{~A}$ & current error \\
\hline \hline
\end{tabular}

Each individual error mechanism discussed in the previous paragraph has been simulated separately. The analysis of the resulting MA en MSD position errors as a function of the corresponding error is discussed in the next paragraphs.

\section{Additive errors}

\section{Offset error}

The current offset error range for which the simulation is run, is set from $-1 \mathrm{~A}$ to $+1 \mathrm{~A}$, corresponding with $1 \%$ of a \pm 100 A output current range, for which the results are shown in Fig. 12. Current offset errors are compensated by the high low-frequency gain of the position controller, causing no significant MA and MSD position errors.

\section{Gain error}

Fig. 13 shows the MA and MSD position errors for a modelled gain error ranging from $-0.01 \mathrm{~A} / \mathrm{A}$ to $+0.01 \mathrm{~A} / \mathrm{A}$. From the results can be concluded that gain error, originating for instance from the current sensor, has a significant influence on position accuracy, increasing to the nanometer range for even relatively small gain errors. 


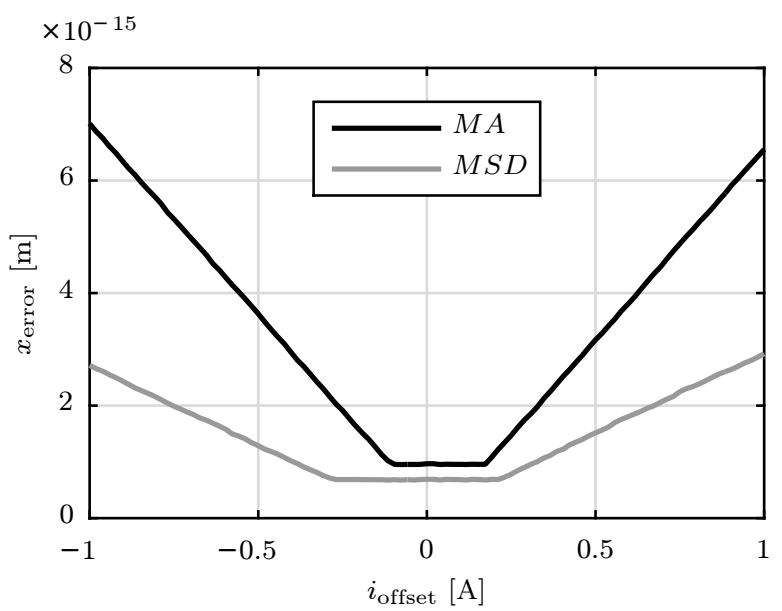

Fig. 12: MA and MSD position error vs. current offset.

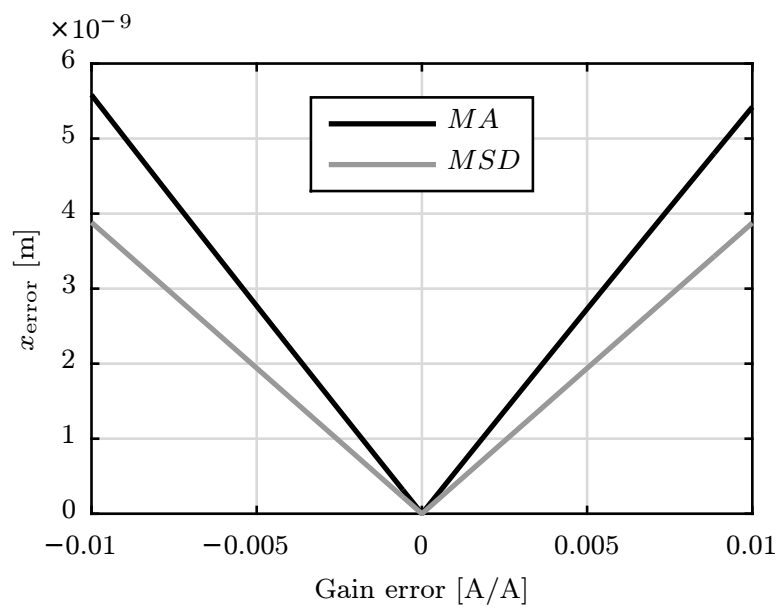

Fig. 13: MA and MSD position error vs. gain error.

\section{Non-linearity error}

Both even and odd non-linearity error functions are simulated for a spatial frequency $f_{\text {spat }}$ range from $0 \mathrm{~A} / \mathrm{A}$ to $50 \mathrm{~A} / \mathrm{A}$, and the respective graphs are shown in Fig. 14 and Fig. 15. The resulting MA and MSD position errors are again in the nanometer range. From the waveforms in both graphs can be concluded that distinct current-spatial frequencies are dominant and determine the potential position error, and thereby the acceptable upper limit for $i_{\mathrm{NL}}$. A correlation exists between $f_{\text {spat }}$ and the spectral content of $i_{\text {set }}$, the latter depending on the mechatronic system parameters. The significance of applying the combined modelling approach for evaluating the performance of the power amplifier is clearly observed.

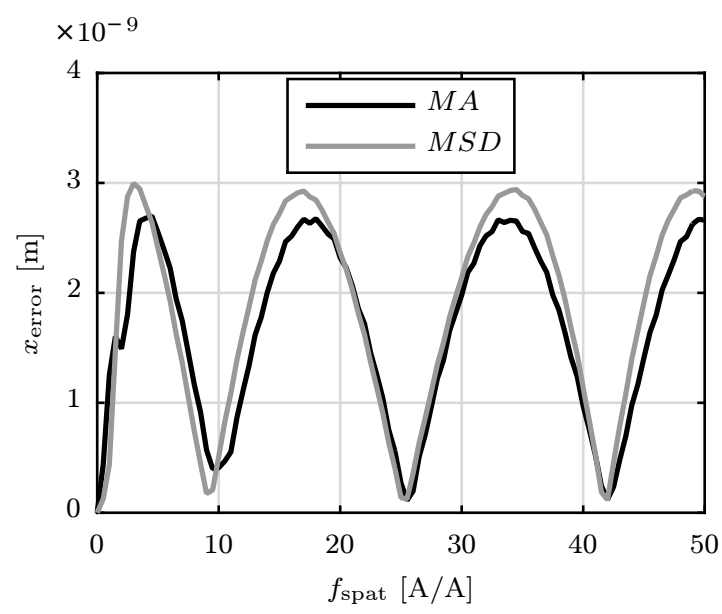

Fig. 14: MA and MSD position error for even nonlinearity as a function of $f_{\text {spat }}$.

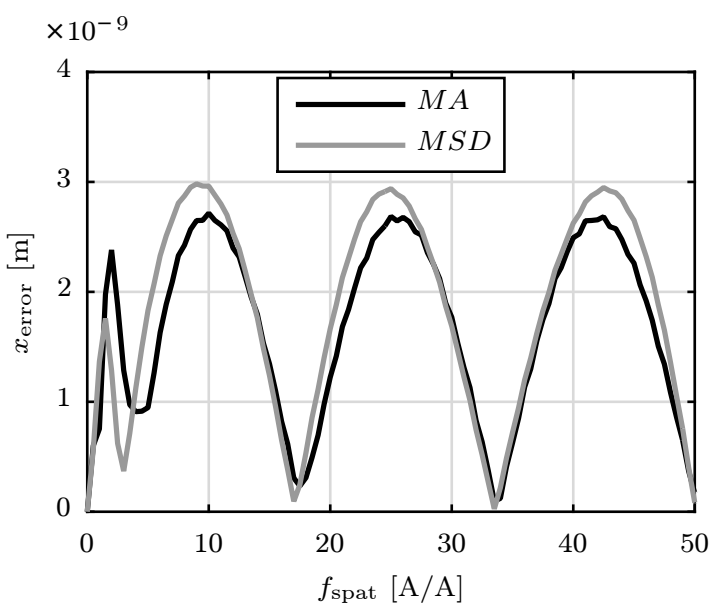

Fig. 15: MA and MSD position error for odd nonlinearity as a function of $f_{\text {spat }}$.

\section{Bandwidth limitation}

In order to obtain the bandwidth limitation of the current-controlled amplifier in the positioning system, the model for the current-controlled current amplifier as described above is simulated for an open-loop bandwidth $f_{\mathrm{bw}, \text { cur }}$ ranging from $5 \mathrm{kHz}$ to $20 \mathrm{kHz}$. The resulting MA and MSD position errors for each simulated $f_{\mathrm{bw}, \text { cur }}$ are shown in Fig. 16, and the values increase significantly for a decreasing bandwidth from $8 \mathrm{kHz}$ and lower. For a bandwidth of $7 \mathrm{kHz}$ or higher, the resulting MA and MSD position errors remain in the order of $10 \mathrm{pm}-50 \mathrm{pm}$, which is relatively small.

The minimum at around $7.75 \mathrm{kHz}$ occurs around a frequency for which most error frequency components cancel out. The location of the minimum is depending on the spectral content of the current reference $i_{\text {set }}$ which depends on the mechatronic system parameters. 


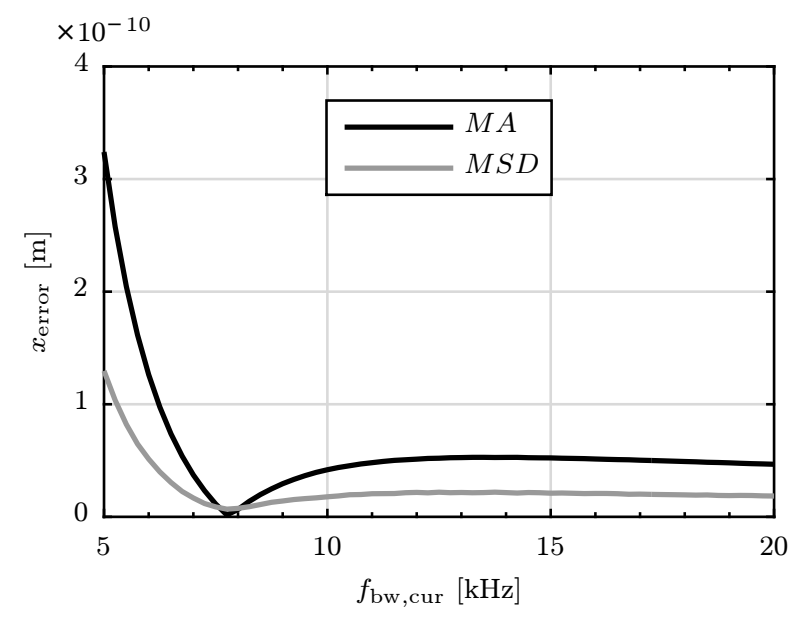

Fig. 16: MA and MSD position error vs. bandwidth.

\section{Conclusions}

A combined model containing electrical, mechanical and control systems is presented that is used to obtain specifications for the performance of a power amplifier in a mechatronic system with position accuracy requirements. An amplifier error model is incorporated that contains additive error components, i.e. current offset, gain error and non-linearity of the output current, and a generic model for a currentcontrolled current amplifier to emulate bandwidth limitation. For a $3^{\text {rd }}$ order motion profile, the MA and MSD position error is determined for a range of values of each individual error mechanism in order to determine its significance.

The added offset current has no significant influence on the resulting position error for a mechatronic system actuated by a linear motor, as it is compensated by the position controller. On the contrary, even a slight gain error results in a significant position error. The same holds for introduced non-linearity errors, though from the simulation results can be concluded that a dependency exist with the specific mechatronic system parameters. Regarding bandwidth limitation, an optimal bandwidth for the current controller seems to exist for the analysed system. Decreasing the bandwidth below the optimum results in a significant increase in position error.

A generic platform has been presented on which extended amplifier error analysis can be conducted and from which boundary specifications can be derived when the required position accuracy of the complete mechatronic system is known. The platform can be extended with increased level of detail in e.g. mechanical model and amplifier electrical model to obtain results that are more correlated to practical applications. Ensuing properly targeted amplifier requirements provide focused amplifier optimisation and mechatronic system design.

\section{References}

[1] R.-H. M. Schmidt, "Ultra-precision engineering in lithographic exposure equipment for the semiconductor industry." Philos. Trans. A. Math. Phys. Eng. Sci., vol. 370, no. 1973, pp. 3950-72, 2012.

[2] H. Butler, "Position control in lithographic equipment [applications of control]," IEEE Control Syst. Mag., vol. 31, no. 5, pp. 28-47, 2011.

[3] J. M. Schellekens, A Class of Robust Switched-Mode Power Amplifiers with High Linear Transfer Characteristics. PhD Thesis, Eindhoven University of Technology, 2014.

[4] E. Lemmen, J. M. Schellekens, C. G. E. Wijnands, and J. L. Duarte, "Advances in High-Precision Amplifiers-The Extra L Opposed Current Converter," IEEE Trans. Power Electron., vol. 30, no. 10, pp. 5691-5700, oct 2015.

[5] J. M. Schellekens, M. L. A. Caris, J. L. Duarte, H. Huisman, M. A. M. Hendrix, and E. Lomonova, "High precision switched mode amplifier with an auxiliary bias circuit," in 2013 15th Eur. Conf. Power Electron. Appl. EPE 2013. IEEE, sep 2013, pp. 1-10. 
[6] H. Butler, "Feedforward signal prediction for accurate motion systems using digital filters," Mechatronics, vol. 22, no. 6, pp. 827-835, 2012.

[7] K. W. Verkerk, H. Butler, and P. P. J. van den Bosch, "Improved disturbance rejection for high precision systems through estimation of the flexible modes," in 2015 IEEE Conf. Control Appl. CCA 2015 - Proc. IEEE, sep 2015, pp. 1191-1196.

[8] M. Boerlage, M. Steinbuch, P. Lambrechts, and M. van de Wal, "Model-based feedforward for motion systems," in Proc. 2003 IEEE Conf. Control Appl. 2003. CCA 2003., vol. 2. IEEE, 2003, pp. 1158-1163.

[9] M. Mauerer, A. Tuysuz, and J. W. Kolar, "Distortion analysis of low-THD/high-bandwidth GaN/SiC class-D amplifier power stages," in 2015 IEEE Energy Convers. Congr. Expo. IEEE, sep 2015, pp. 2563-2571.

[10] H. Butler and W. Simons, "Position Control in Lithographic Equipment," in ASPE 2013 Spring Top. Meet. MIT Lab. Manuf. Product. Annu. Summit, 2013, pp. 7-12. 